\title{
DECENTRALIZED ADMINISTRATIVE TECHNIQUES OF THE FEDERAL GOVERNMENT
}

\author{
Albert S. AbeL*
}

$\mathrm{D}$

ECENTRALIZATION of governmental activity in its simplest sense means mere geographical dispersion. ${ }^{x}$ Reference even here may be to either of two things-dispersion of governmental total activity or dispersion of the personnel and offices of a given division within the larger organism. The former has been in the forefront of recent discussion, with the Grazing Service moved to Salt lake City, the Home Owners' Loan Corporation to New York, and proposals afoot in our defense-jammed capitol for legislative extension of this policy. ${ }^{2}$ Basically there is nothing new in all this. While some of the founding fathers thought of the federal city as a gigantic leech wherein the federal offices and officers would be absorbed, in practise the executive and judicial branches were from the beginning and from necessity strewn throughout the states. Congress alone was confined to Washington, and even it only in its formal legislative capacity.

This aspect of decentralization holds little specific interest for our present task of investigating the extent to which this federal union still remains federal. This is not to deny that as a problem of public administration physical dispersion poses interesting questions, such as the allocation of particular activities to appropriate localities, the effective utilization of existing available space to prevent such repetitions of the Washington housing situation as exists in Baltimore, and so on; but these are matters more proper for consideration elsewhere.

Particular agencies, moreover, have been subject to the same geographical dispersion. The collectors of the customs, the postoffices, and the army personnel have been scattered for longer than there has been a union. We may suspect that there is a greater proportion of the federal personnel now located in Washington than was stationed in New York in I790; I know of no statistics to prove this, however, and the supposition may well be erroneous. ${ }^{3}$

\footnotetext{
* Associate Professor of Law, West Virginia University, College of Law. On leave to United States Navy.

× Cf. Report of the President's Committee on Administrative Management 30 (1937).

$=$ Time Magazine, Sept. 29, I94r, p. I7, col. 4.

3 At the time the monographs of the Attorney General's Committee on Administrative Procedure were prepared, the Tariff Commission had 301 employees at central headquarters
} 
This matter of organization within a given agency is of more pressing importance, however, than that of the overall scatteration of federal activities. The composition of the agency personnel points up the problem. Insofar as there is a correlation between the residence of employees and the areas they serve, geographical dispersion is connected with localism and thus with federalism. Indeed, the relations of some federal employees, notably postmasters and customs officials, with their home communities and home politics have occasionally been so intimate in the past that they have at times been thought to be a stink in the nostrils. That again is another story; but it does emphasize that the recruitment of the federal personnel is one obvious channel by which elements of decentralization may be introduced into the federal government.

Conversely, where a policy of local selection is not followed, the federal agencies are or may be quite centralized even though the field force is scattered throughout the nation. The army is a classical instance. Partly no doubt this is a special case of a strong professional tradition to a degree blunting local sensibilities. At any rate, there is no special attachment to the assigned place of duty. If state allegiance was paramount to Lee, it was Arlington and not West Point which claimed his loyalty. Quite aside from the military, the evidences are strong that dispersion often does not mean decentralization if a policy of assigning employees to their home communities is not pursued. Much bitter current comment on new or extended federal activities has behind it little more than the circumstance that outlanders have come in to administer the laws. As a matter of political strategy, it may be open to question how far it is wise

and nine in the field; the Federal Power Commission 590 and 200 respectively; the Bureau of Marine Inspection and Navigation about rooo and about 400; the Federal Communications Commission 425 and 193; the Interstate Commerce Commission 1867 and 8Io; the National Labor Relations Board 485 and 388 ; the General Land Office 309 and 276; the Maritime Commission about 1200 employees, somewhat over half of them in Washington; the Railroad Retirement Board 2700 employees, "roughly half" in Washington; the Wage and Hour Division had 486 at headquarters and 670 in the field; the office of the Comptroller of the Currency 542 and 755 respectively; the Packers and Stockyards Division of the Agricultural Marketing Service 35 and 63 ; the Bureau of Internal Revenue 4200 and $x 8,400$; the Grain and Seed Division of the Agricultural Marketing Service 28 and $28 \mathrm{r}$; the Bureau of Customs 189 and 8252 . Attached to the Federal Reserve Board were about 400 employees while some $I x, 000$ were connected with the rest of the Federal Reserve System; and the civil employees of the Corps of Engineers, War Department, numbered approximately 300 in Washington and varied from 70,000 to 150,000 in the rest of the country. Breakdowns for other agencies are not available, but the above list exhibits a marked difference among the agencies, with the major proportion of employees detached from the central office in many instances.

All figures are from the monographs, which are the principal source relied on in the preparation of this paper. Although local citation to the monographs will only occasionally be made, all descriptions of agency practises and statements of specific fact not credited to others are derived from them. 
to offend the prejudices and sentiments of a community by requiring it to do business with a fellow citizen who acts justly and speaks wisely but with the accent of another section. Overriding considerations are vastly more important than this detail of public opinion; yet in its petty way it bears upon decentralization by showing that there are elements involved in it which mere scatteration does not reach.

A second sense in which the term decentralization has been used is to express the notion of a devolution of responsibility. Thus employed, it denotes the matters usually phrased in the language of delegation and subdelegation.

Delegation is a fundamental question in every consideration of administrative law and organization. Practically speaking, something of it is necessarily present whenever the amount of business within the area of control becomes more than the administrative officer or board at the top can handle. Only as the allocation of jurisdiction, initial or ultimate, over particular phases within the total realm of action becomes formalized and regularized, however, is it possible to study or discuss decentralization from this approach. The forms it has assumed in practise are far too various even to be mentioned within available limits. They may be ranged, however, under two main heads. First, there is the method of devolution of responsibility among the members of a board or commission by adoption of a divisional structure and a corresponding compartmentalization of attention. Second, there is devolution from the primary authority to subordinate individuals or groups within the organization. Each of these and characteristically both in combination have been used, in almost every conceivable mutation, in the effort to cope with the vast and complex body of matters falling within the purview of the administrative process.

Congress has on occasion decreed a divisional distribution of control at the upper administrative level by the basic statutes. Here the divisions are less apt to be within a single agency than among a number of coordinate authorities. The Congressional scheme may take shape as a relatively deliberate, well-articulated design, as in the case of the Civil Aeronautics Board, the Civil Aeronautics Administrator, and the former Air Safety Board; or it may emerge from a group of haphazard enactments which compel the agencies established to settle among themselves what each shall do, as in the case of the Comptroller of the Currency, the Federal Reserve Board, the Federal Deposit Insurance Corporation, and to a degree, the Reconstruction Finance Corporation.

More commonly, the divisional structure is internal to the agency and 
created on its own initiative, without express mandate. Most multipleheaded agencies are illustrative. Instances range from the Maritime Commission, each of whose five members by more or less tacit understanding concentrates largely on some aspect of its activities as to which he possesses special interests and qualifications, to the Interstate Commerce Commission. The I.C.C., Congressionally authorized and formally established, has five divisions of three assigned members each; each division has a regularly defined function, and over a period of years a somewhat fluctuating composition. The whole is accompanied by a collateral framework of special committees, of supervision over the various bureaus and sections by individual commissioners, and of participation ad hoc by commissioners in the work of divisions of which they are not regularly members.

But if a descriptive treatment of decentralization by establishment of divisions at the upper level is difficult, it is simplicity itself compared to decentralization by the confiding of responsibility to subordinates. The tremendous assortment of administrative duties imposed by statute or presidential order in various cabinet members, notably the Secretaries of Agriculture and of the Interior, can be discharged only by extensive reliance on others within the department. A similar situation exists where a single-headed independent authority, such as the Veterans' Administration, is set up. Where multiple-member agencies are involved, the need for and use of assistance is substantially as great. The five Federal Trade Commissioners, the seven members of the Federal Reserve Board, the seven Communications Commissioners cannot possibly attend to all the details or even to all the more important types of action coming under the relevant statutes. The authority vested in every considerable donee of administrative power in the federal system is and must be parcelled out to inferiors, with the process continued on down the line again and yet again. A graphic chart of any major administrative agency strikingly resembles a genealogical table with the topmost authority as the remote ancestor-sometimes very remote indeed.

No more than geographic dispersion do elaborate delegation and subdelegation infallibly establish the presence of decentralization in any true sense. The grant or denial of the second-class mailing privilege is a case in point. Here the Postmaster-General has confided jurisdiction to the Third Assistant Postmaster-General, who has in turn entrusted it to the Division of Classification in his office, which itself is divided into special groups, one of them dealing with problems as to second-class matter. It is this special group which effectively disposes of applications for the second-class mailing privilege, save in exceptional instances where determina- 
tion is by the Solicitor. Although disposition of such cases is thus thrice removed from the Postmaster-General, one would scarcely dub this an instance of decentralized administration.

Notwithstanding implicit recognition that the administrative process may be centralized despite geographic dispersion and again despite extensive employment of delegation or of a divisional structure, recent usage tends to fuse without articulating these two elements and to speak of decentralization as the condition existing where both are present. Thus, the recent change in the procedures of the Bureau of Internal Revenue, commonly referred to as decentralized in contrast with the prior centralized system, combines substantial scatteration with substantial delegation. ${ }^{4}$ Again, the majority members of the Attorney-General's Committee on Administrative Procedure, in advocating decentralization, reveal by the context that they are thinking of a scheme marked by the two together. 5

Occasionally the decentralized pattern, using decentralization in this currently popular sense, is chosen by Congress. An extremely interesting form is that afforded by the government corporation: the TVA and kindred regional authorities suggest techniques and devices for decentralization that deserve a volume instead of this passing sentence. ${ }^{6}$ Elsewhere, as in connection with the United States Employees' Compensation Commission and the related functions of deputy commissioners, Congress, in a less original mood, has simply conferred on local representatives rather extensive discretion and powers within the framework of a single roughly integrated agency.

More commonly, decentralization is inaugurated by the superior administrative officials, and it springs in large measure from their effort to break down the volume of work into manageable chunks. Its specific form represents a compromise, dictated by experience, between the need for dispatching business as it arises and the need for preserving some minimum of overall guidance and control. ${ }^{7}$ Since federal administrative

4 See Monograph 22, Attorney-General's Committee on Administrative Procedure 42 et seq. (1940).

5 Report of the Attorney-General's Committee on Administrative Procedure 24 (I94x): "Closely related to the problem of delegation is that of decentralization. Some agencies have been decentralized to a large extent. ... . The Committee is convinced that the convenience of the public may be served and administration improved if those agencies which are in a position to do so will vest in field officers greater powers to deal with the persons whom they regulate."

6 Report of the President's Committee on Administrative Management 39 (I937).

7 Henry A. Wallace, Emerging Problems in Public Administration, 34 Am. Pol. Sci. Rev. 228 (I940): "Just as physical limitations require the executive at the top thus to organize his function, so do physical limitations of the whole Washington staff dictate a growing decentrali- 
activity encompasses matters as diverse as allowance of claims of creditors of dead Indians, supervision of proxy solicitations in corporate elections, censorship of the labels on whiskey bottles, and prescription of the basic relations between radio networks and subscribing broadcasters, it seems natural that the allocation of responsibility between center and periphery should be similarly diverse. Putting aside the service and the housekeeping functions of the agencies, and focusing on their legislative and judicial activities, as to which materials are more accessible, the variety which remains is a monument to human ingenuity. Since the business before the agency molds the procedures evolved to dispose of it, there is no one optimum point or pattern of federal administrative decentralization. Instead, there is for each agency and task a different best arrangement, which may be only a temporary one even for it.

To repeat, the decentralization we are considering at the moment has two elements-geographical scatteration and devolution of responsibility. Geographically, a common arrangement is to provide a number of regional authorities under the central administrative, and further to subdivide the work between district or local representatives under each of these. Sometimes the hierarchy blankets the country; -where matters are involved peculiar to a section, however, no provision may be made for other areas. Often either regional or local offices may be elided. If the former are omitted, locals deal directly with the central agency or some branch, bureau, or official attached to it. If local or district offices are omitted and only regionals provided, the latter are likely to have travelling field representatives to establish the spot contacts with the persons regulated. Travelling field representatives constitute, indeed, a distinctive method of decentralization which may appear along with any type of administrative hierarchy mentioned or quite independently of such a hierarchy. Sometimes they are circuit riders making roughly periodic visits, sometimes flying squads to look into suspected matters, sometimes troubleshooters sent in response to $a d$ hoc requests for special assistance by individuals or by the localized personnel. Ordinarily, decentralization is greater under a régime of regionals and locals than where only itinerant field representatives are used. It is normally greater under the circuit-riding scheme, especially if representatives spend most of their time away from headquarters, than

zation of administration into forms, locations, and personnel that continually are refreshed and checked by closer association with the people for whom the programs exist. As there is more centralization of policy determination and more complexity of governmental functioning, there must be more decentralization in administration. Yet this must be a decentralization that makes the policy fully effective-a decentralization that does not defeat policy nor surrender responsibility." 
where a reservoir of agents at the central office is detailed to occasional special duty in the field. In a true sense, though, all these variants involve geographical dispersion. Choice among them is not always dictated by considerations of policy; it may rest on nothing more fundamental than the generosity or niggardliness of Congress in appropriating for the agency. The many gradations of decentralization are most striking, making it well nigh impossible to classify an agency even on a purely geographical basis as centralized or decentralized. Instead it is ordinarily a question of more or less.

The data on the delegation element in decentralization are even harder to summarize in orderly outline than are those on scatteration. From first awareness of a problem potentially meriting consideration until culmination in final, formal disposition, many stages in the process of judgment may be identified. These are not peculiar to administrative action but are present in all organized group action-even, although much obscured, in the forming of private personal decisions. But the elaborate and relatively formalized way in which administrative agencies reach and announce their conclusions renders the several stages more than ordinarily conspicuous. Whether the end product be called a decision or a regulation or whether the judgment involved be thought of as judicial or legislative, makes little difference as to the stages in the corporate intellectual process. More fruitful than such conventional categories is the recognition that judgment is involved at each of the following points: (I) initiation of action; (2) preliminary disposition as of course; (3) reception and examination of protests against such preliminary disposition; (4) control over the preparation and presentation of probative and persuasive materials in the event of dispute; (5) tentative initial reasoned determination; (6) final initial disposition; (7) intermediate reconsideration; (8) ultimate disposition, typically embodied in a formal regulation or adjudication. Even this list omits the stage of pro forma approval by a titular superior, sometimes prescribed by statute, and the ever present possibility of recourse to extraneous authorities such as courts, both no doubt relevant but both rather adjuncts to than elements in the administrative process.

Two of these eight stages, namely, initiation of action and ultimate disposition, are inevitable in even the simplest structural scheme. Any of the others may be omitted, and the variety of provisions made for them is infinite. Ordinarily the several stages tend to flow into each other, and it is only in the busiest agencies with the most elaborate procedures that distinct recognition of all of them is found. Some of them, notably re- 
consideration after final initial disposition, may be allowed repeatedly. But each represents a moment at which any agency might and some do vest actual effective disposition in the subordinate personnel. The more completely a subject is left at an early stage to subordinate determination by persons geographically dissociated from the central office, the greater the decentralization.

The discretion granted subordinates at any stage is generally in inverse ratio to the frequency with which discretion at that level must be exercised. Thus, over initiation of action (which includes the policing and inspection functions), and over preliminary dispositions as of course, local representatives characteristically have extensive dominion; over ultimate formal disposition rarely so. The decentralizing technique consists in large part of the procedures by which invocation of discretion at the next higher stage is discouraged, and the volume of work at each succeeding level thus diminished.

One must not overstress the quantitative aspects of delegation. Inquiry as to how often there can be or is effective termination at an earlier stage of the administrative process, should be supplemented by qualitative inquiry as to the content and character of the matters so terminated. Most studies deal with the availability of techniques for upsetting determinations, while our central concern is with practises actually followed in letting them stand. Decentralization is characterized not by the contingencies under and devices through which staff determinations may be disturbed, but by the circumstances under which in day to day operation they remain undisturbed. Appraisal of delegation involves primarily a quest for a coherent even if unarticulated pattern and philosophy of administrative inertia at the upper levels.

Roughly, the tendency is for the superiors to reserve value judgments and inferences from facts to themselves, while leaving matters which are predominantly objective, or those as to which veracity and the opportunity for observation are paramount, to subordinates. Where objective elements preponderate, decentralized determinations flourish; as the area of discretion increases, that of delegation tends to decrease. Determinations of credibility (often left to subordinates) are perhaps only an apparent exception, since whether a man is speaking truth or lying is after all a raw fact although by no means a simple one; or, if a real exception, they are of very special character-which leaves intact the major proposition that in practise delegations tend to cluster about the pole of objectivity and to shun that of discretion.

This doubtless accords with what Congress had in mind in enacting the 
basic statutes. The trouble is that jesting Pilate was right in asking, "What is Truth?" Questions of mathematical computation or of formal compliance with formal requisites for applications, protests, and so on, are almost devoid of subjective content and are almost universally left to the very lowest rank in the administrative hierarchy. Somewhat less clear but still tolerably objective are questions involving "real evidence," especially in the domain of the physical sciences; so that field determinations, by examination or test of the proof of alcoholic beverages, the conformity of locomotive boilers and railroad safety appliances to engineering standards, or the grading of grain, involve at most a negligible amount of discretion. Even when the issues move into the less exact biological and social sciences, the increased role of discretion is not necessarily obvious: the extent of a veteran's disability and whether it is service-connected, the appraisal of accounting statements and customers' contracts to determine whether the incidence of a processing tax has been shifted, the valuation and quality of the financial backing available to an applicant for a broadcasting license-how far is judgment as to such matters objective and how far discretionary? Or, advancing still further toward the discretionary without wholly throwing off the objective, consider the questions of whether a bank's operations have been in accordance with sound banking practises, of whether the obligations of a deceased tribal Indian are bona fide allowable debts against his estate, of the effect upon navigability of proposed alterations in a bridge across an interstate stream, of the existence and size of the bona fide subscription list of a periodical-these are questions which must be determined by some one of the federal administrative agencies.

The intricate variety of current practise respecting delegation traces to this hybridity in many of the questions presented. Those almost purely objective rarely reach the upper levels; those almost wholly discretionary (e.g., the appropriate reserve ratio for member banks, the qualifications and compensation of attorneys appearing before administrative tribunals, the propriety of exemption from the integration provisions of the Public Utilities Holding Company Act) rarely escape them. In between there is all manner of diversity within and among the several agencies. So at most a relative answer can be made as to whether a given agency is decentralized. Each is more nearly so the greater its readiness to leave undisturbed the decisions of subordinates which include relatively considerable discretion.

Lawyers, and to a degree the agencies themselves, have been bemused in this connection by the hoary distinctions between legislative and judi- 
cial action, and between questions of fact and those of policy or law. A tendency is evident in most agencies to allow more finality to staff decisions smacking of the traditional judicial grist than to staff rulings analogous to ordinances. ${ }^{8}$ Similarly, the lawyers tend to demand, the agencies to grant, and the courts to approve greater delegations as to "issues of fact" than as to matters of "law" or "policy." This threshing of old straw seems to me a crude approach to the important issues which such borrowed concepts very imperfectly formulate.

If one must follow legal analogies, a more useful reference might be to the distinction laid down in Cooley v. Board of Wardens, ${ }^{9}$ i.e., between interstate commerce national in character and interstate commerce local in character. That might be serviceable in allocating the controlling exercise of discretion between central authority and outlying members, with its suggestion that what is common and general be reserved for unified treatment from Washington, and what is special and particular be entrusted to localized bodies. The considerations which underlie the federal structure of our government, while sufficiently lessened in force that federal legislation may now be called for in fields hitherto unoccupied, may still suggest an appropriate division of responsibility within the federal agencies. ${ }^{\text {ro }}$ While discretion is, generally speaking, for the superior authority and objective facts for subordinates, almost always they concur and intertwine; perforce the authority delegated must include power to make decisions which involve discretionary ingredients. The line to be drawn is between the effective discretion parcelled out and that withheld. The Cooley case test premises that the local milieu in which a policy decision is to operate may itself be a fact important enough to condition substantially the content of the policy determination. There are some traces of a perhaps unconscious inclination in various agencies to accept the test in fashioning their pattern of decentralization. In support of this inclination it should be noted that local peculiarities often account for an increment of special objective facts. Indeed, this choice may be an excellent determinant of delegations of discretion. ${ }^{\mathrm{Ix}}$

${ }^{8} \mathrm{~A}$ striking instance is afforded by the Bureau of Internal Revenue, whose case-determining functions are an example of decentralization par excellence while, in issuing regulations, even a rudimentary consultative practise is lacking and the whole process of initiating and deciding is monopolized by the Washington staff. See Monograph 22, Attorney-General's Committee on Administrative Procedure I43-I47 (I940).

9 I2 Howard 299 (1852).

ro See remarks of J. A. Corry, The Federal Dilemma, 7 Canadian J. Econ. \& Pol. Sci. 227 (I94I).

1I Charles Beard, Administration, a Foundation of Government, 34 Am. Pol. Sci. Rev. 234 (I940): "Unless .... a an administrative system is so constructed and operated as to keep 
Structurally, the elements of geographic dispersion and devolution of responsibility tell the whole story of administrative decentralization. It is a story not peculiar to the federal government, nor indeed to political groups. The same elements have been observed as the characteristics of decentralization in a recent acute analysis of large-scale business enterprise; $;^{22}$ and accounts of such concerns as the International Harvester Company are very like descriptions which might be given of many federal agencies, ${ }^{13}$ even those commonly regarded as relatively decentralized in operation. Yet, analysis of these elements falls short of a true and full picture of decentralization because the accepted meaning of decentralization is defective.

It is unreal in that it isolates each agency and treats it in vacuo, whereas the agencies exist as components in the larger political and social organism. Decentralized techniques are centrifugal, differentiating devices by which effective responsible participation in government can be shifted from center to periphery. Statistically, participation by the agency staff does bulk largest in volume, thus making it easy to think of decentralization as a question of internal structure; actually, however, outsiders also share in the administrative process. Such extra-mural participation is perhaps as significant though not as routine a decentralizing device as anything in the agency's organization.

One can only mention here the outlying phases-the extent to which agencies rely on or accept participation of interested individuals as individuals, the nature of their relations with Congress, the interactions of judicial and administrative bodies. More pertinent are the relations between the agency and other federal agencies, between the federal agencies and the states, and between them and non-governmental groups or associations of a social, professional, or economic character.

Inter-agency relations bear rather remotely on decentralization. Not wholly alien, since they do present situations where the experience or judgments of persons other than the heads of the particular agency involved are of controlling importance, they nevertheless depart from a centralized pattern only so far as to give weight to other administrative

alive local and individual responsibilities, it is likely to destroy the basic well-springs of activity, hope, and enthusiasm necessary to a popular government and to the flowering of a democratic civilization."

${ }_{22}$ Marshall E. Dimock and H. K. Hyde, Bureaucracy and Trusteeship in Large Corporations, Monograph Ir, T.N.E.C. 82-84 (r940).

${ }^{{ }_{3}}$ J. T. Dunlop and E. M. Martin, Industrial Wage Rates, Labor Costs, and Price Policies, Monograph 5, T.N.E.C. 76 (I940). 
bodies, potentially as centralized as the agency exercising jurisdiction. It is still the federal government acting. Except as differences in objectives or methods have resulted in somewhat different attitudes between agencies, deference to the views of other members of the administrative family does not substantially modify the degree of centralization consequent upon the internal structural pattern of the particular agency. Typically, it is manifested either by acceptance of the conclusions of parallel agencies having similar duties in allied fields, or by permitting or soliciting other agencies conceivably interested in the subject at hand to present their views. In the former case, determinations of the sister agency are adopted as the data of judgment, which sometimes approaches slavish imitation. The following are typical: the Railroad Retirement Board's reliance on Interstate Commerce Commission determinations of carrier status for coverage purposes; the licensing of ship radios and operators by the Bureau of Marine Inspection on the basis of recommendations from the Federal Communications Commission; and the tendency of junior agencies in the field of utility regulation to reproduce procedural techniques of the Interstate Commerce Commission. The other major device, namely, seeking the views of outside agencies whose interests are affected, is exemplified by the Customs Bureau references to the Bureau of Animal Industry, the Bureau of Biological Survey, or others in connection with prohibited importations; by Bureau of Fisheries consultations with the Coast Guard and the Bureau of Customs before promulgating whaling regulations, and the like. Essentially, it is a branch of diplomacy; the practises involved rest on inter-agency comity. It may lead, where agency powers are contiguous or overlapping, either to joint occupation of a field, to a definition of their respective jurisdictions, or in extreme cases to adoption of some divisional arrangement such as was mentioned earlier.

Decentralization is more patent where the extrinsic reference is to political authorities outside the federal administrative family. This means participation by states and occasionally by municipalities or like units. State participation is most common in utilities regulation and in administration of federal social welfare programs, particularly those implemented by conditioned grants to the states.

The co-existence and frequently pre-existence of comparable state regulatory bodies in the utilities field, with staffs and procedures tolerably adequate even if seldom anything like as informed as their federal parallels, make collaboration peculiarly useful. Moreover, division of jurisdiction on the fortuitous basis of whether transactions are interstate or intrastate, 
and the great need for the federal agency to understand local conditions and sentiments in view of the grave consequences its action may have upon the internal economy of the state, make collaboration especially imperative. It is not surprising, therefore, that utility regulation is the preeminent instance of decentralization by collaboration with the states. The basic Congressional statutes frequently envisage it, and the administrative authorities, particularly in the more mature agencies, incline to accept the spirit of the statutes by allowing state representatives a generous share in the regulatory scheme.

The social welfare agencies seem by no means so ready to permit effective state participation. While the federal program's very framework has at times been dictated by constitutional doubts as to whether state collaboration could be dispensed with, it is perhaps fair to say that the federal administrative authorities have entertained sincere and all too often legitimate doubts as to how far some state authorities favor the program proposed. The statutes have created an intimate link between state and federal action, making the former an essential part of the administrative scheme; the agencies, through control over the subventions available to the states, have tended to make that link, not a decentralizing device for delegating discretion to and deriving assistance from state authorities, but a centralizing control by which uniformity of treatment may be induced throughout the union, in derogation of particularism and local circumstance. Thus, state participation has operated by a strange paradox to thwart decentralization, because it has been made mainly instrumental and stripped of a responsible sharing of discretion. Still, the statutory pattern is well calculated to produce decentralization; and perhaps that will be the eventual outcome, once the federal authorities are satisfied of good faith adherence by the states to the objectives and minimum standards proposed, and if the tradition of federal supervision of minutiae does not meanwhile become too firmly established. This prediction seems justified by the Canadian and Australian practises concerned with conditional grants to the constituent provinces or states. ${ }^{\mathrm{I}}$ Those federations, much more experienced than we in the field of federal subsidies, have things to teach us about their use without loss of flexibility or destruction

\footnotetext{
${ }_{14}$ The various phases of the problem have been extensively investigated; see, e.g., Commonwealth Grants Commission, Reports on Applications by South Australia, Western Australia, and Tasmania for Financial Assistance under Section 96 of the Constitution (I934, I935, and 1936); Wilfred Eggleston and C. T. Kraft, Dominion Provincial Subsidies and Grants (r939), a monograph prepared for the Royal Commission on Dominion Provincial Relations. For surveys of the American experience, consult V. O. Key, The Administration of Federal Grants to States (1937), and A. F. Macdonald, Federal Aid to the States, 34 Am. Pol. Sci. Rev. 489 (1940).
} 
of local autonomy. With tax resources available to the states decreasing, and dependence on federally raised funds to support governmental services increasing, the development in this area of wise practises as to decentralization by collaboration with state authorities is of high importance.

Thirdly, there is extra-mural decentralization involving participation by non-governmental groups or organizations. Especially in connection with administrative rule-making do such bodies have an important role, although their part in administrative adjudication is by no means negligible.

One useful consequence of joining them in what is done is the opportunity for educating them and through them the public. In a democracy, administrative agencies must persuade the people of their fairness and efficiency. Giving those affected by government regulation a chance to watch the wheels go round is a potent means to that end. To choose diverse instances, the National Labor Relations Board's policy of permitting employee representation by union representatives in unfair labor practise cases, the Securities and Exchange Commission's conferences with investment trust company officials preliminary to recommending legislation to Congress, and the Federal Reserve Board's submission to the American Bankers' Association of proposed regulations, all seem wisely devised to generate understanding.

Here, too, one may note the relations between administrative agencies and the legal profession. The bar is not merely an occupational classification. It is a cohesive group whose members are all measurably indoctrinated with common notions and which, moreover, has both an extraordinary number of contacts with the agencies and an extraordinary influence upon public reactions to them. This influence is partly attributable to the public's assumption of lawyers' special familiarity with matters governmental, more largely perhaps to the superior articulateness of the legal profession. It has always shown a lively concern with administrative action,' especially on the procedural side, although often enough its concern radiates more heat than light. In the skirmishes over the unlamented Logan-Walter Bill, the Federal Bar Association took its stand in support of unhampered administrative action; still more significantly, many of the specialized bars annexed to particular agencies defended the procedures with which they were familiar so strongly that their protégé agencies were named within that bill's strange medley of specified exceptions. In view of these activities, the agencies might be wise to let the bar share in the formulation of administrative procedures. Thus, they may well 
establish sufficient understanding of their problems to enlist its adherence or at least to disarm its opposition. This is not to say that the administrative should tamely subscribe to legal preconceptions which would impair efficiency; but much might be gained by making concessions in incidental details and by familiarizing lawyers with the complexities that compel departure from cherished procedures at other points.

Private group participation is primarily important, however, in promoting flexibility and better adaptation to special conditions, with education only a collateral function. Thus, it serves the same principal end as do delegations within the agency and state collaboration. Once more, instances are legion. Common devices include regularized practice of consultations or conferences with interested industrial and social groups preliminary to promulgation of regulations, and reference to such groups of proposed regulations. Procedures developed by some agencies regarding intervention or the filing of briefs in administrative hearings operate similarly. In these ways the channels of communication or persuasion are kept open to the representative segments of the public most directly affected by agency action.

Devices for integrating private groups in the administrative structure are still more significant. The advisory committee has been employed in every variation, from its simple, unformalized use by the Bureau of Fisheries, to the elaborate and complicated system of Industry Committees under the Fair Labor Standards Act. Specialized group representatives, having a quasi-official status and corresponding unique opportunities for guiding administrative discretion, range from functionaries such as the Tribal Attorney of the Osage Indians to the Office of Consumers' Counsel in the Department of the Interior, charged with representing the consuming public before the Bituminous Coal Division. Bituminous coal regulation also offers an instance in its scheme of district boards in which an industry, without quite being merged in the administrative, is closely associated in the administrative process. The Civil Aeronautics Authority's issuance of initial airworthiness certificates upon certification that the particular aircraft was manufactured under a production certificate, and the Railroad Retirement Board's utilization of carrier employees as claims agents to report days of labor lost, exemplify a practise of leaving initial action primarily of a formal character to private persons outside the agency, even though such action is dispositive of the case. Perhaps the most definite delegation to extra-political groups is seen in the National Railroad Adjustment Board. The topmost administrative authority in its field, it is composed not of officials but of arbitrators representing the 
carriers and the employees affected by its determinations. Conversely, the extreme in vagueness is represented by the collaboration of the Veterans' Administration with veterans' organizations. Representatives of the latter are housed in the Administration's quarters, consulted by its staff, given special statutory recognition, and actively engage in disposing of veterans' claims; yet the manifold functions of these organizations are as undefined as they are substantial. These examples at random from a wilderness of instances may seem unrelated; but on analysis they reveal themselves as means for shaping administrative action to take account of the demands of special interest groups peculiarly related to some area of governmental action.

The analogy is clear between these devices and the theory, recently much discussed by political scientists and embodied for instance in the Constitution of Eire, ${ }^{15}$ of representation of occupational, cultural, and similar non-regional groups in the. processes of government. While legislative representation on such unconventional bases is and may be for the indefinite future a speculative plaything, the administrative agencies are putting the idea into actual operation.

This treatment of administrative decentralization is perforce only suggestive. If merely a descriptive statement of internal agency structure in the way of geographical scatteration and delegation of discretionary decision were involved, the ramifications are such that, in Mr. Justice Frankfurter's favorite classroom phrase, "Somebody ought to write a book about it." Yet, that aspect of decentralization is simple and familiar compared with decentralization by reference to those outside the federal administrative fold. It has been my endeavor to suggest how, in this latter, tentative solutions are emerging to two fundamental problems of nationalpolitical organization-the problem of how regional interests and state autonomy shall be recognized, now that emphasis is shifting from their treatment in terms of constitutional compulsion to their treatment in terms of political wisdom, and the problem of how particularistic elements of a non-regional social or economic character are to find expression and representation. In the broken contours of administrative decentralization in this larger sense, there are hints and suggestions of the pattern of federalism tomorrow. (I940).

${ }^{15}$ A. W. and M. C. Bromage, The Vocational Senate in Treland, 34 Am. Pol. Sci. Rev. 5 Ig 